\title{
Materials and Devices Research of PPV-ZnO Nanowires for Heterojunction Solar Cells
}

\author{
Zhang Xiao-Zhou, ${ }^{1,2}$ Jian Xi-Gao, ${ }^{1}$ and $\mathrm{Zu} \mathrm{Li-Wu^{2 }}$ \\ ${ }^{1}$ School of Chemical Engineering, Dalian University of Technology, Dalian 116012, China \\ ${ }^{2}$ College of Materials Science and Engineering, Qiqihar University, Qiqihar 161005, China
}

Correspondence should be addressed to Jian Xi-Gao, jian4616@dl.cn

Received 7 October 2011; Revised 15 December 2011; Accepted 29 December 2011

Academic Editor: Sevan P. Davtyan

Copyright (C) 2012 Zhang Xiao-Zhou et al. This is an open access article distributed under the Creative Commons Attribution License, which permits unrestricted use, distribution, and reproduction in any medium, provided the original work is properly cited.

\begin{abstract}
Bulk heterojunction photovoltaic devices, which use the conjugated polymer poly(2-methoxyl-5-(2'-ethylhexyloxy)-1,4phenylenevinylene) (MEH-PPV) as the electron donor and crystalline $\mathrm{ZnO}$ nanowires as the electron acceptor, have been studied in this work. The $\mathrm{ZnO}$ nanowires were prepared through a chemical vapor deposition mechanism. The dissolved MEH-PPV polymer was spin-coated onto the nanowires. The scanning electron microscope images showed that the $\mathrm{ZnO}$ nanowires were covered with a single layer of the polymer, and these materials were used to design a heterojunction solar cell. This solar cell displayed improved performance compared with the devices that were made from only the MEH-PPV polymer. This observed improvement is correlated with the improved electron transport that is perpendicular to the plane of the film. A solar power conversion efficiency of $1.37 \%$ was achieved under an AM1.5 illumination.
\end{abstract}

\section{Introduction}

In recent years, bulk-heterojunction photovoltaic devices that are based on conjugated polymers combined with inorganic semiconductor nanoparticles have attracted significant attention, and a significant amount of scholarly research has been performed in this field [1-3]. These bulk heterojunctions, which consist of hybrid polymers and inorganic nanoparticles, take advantage of the beneficial properties of both types of materials. Specifically, the properties of conjugated polymers, including their unique processability, band gap tenability, and mechanical flexibility, possess excellent possibilities for the fabrication of low cost and highly efficient large area flat-panel displays $[4,5]$. These devices utilize the high electron mobility of the inorganic phase to overcome the charge-transport limitations that are associated with organic materials.

Several hybrid bulk heterojunction polymer solar cells have been reported, including $\mathrm{ZnO}$ nanoparticles $[6,7]$, CdSe nanodots [8], $\mathrm{TiO}_{2}$ nanoparticles [9], and $\mathrm{PbS}$ nanoparticles [10]. Huynh et al. found that using nanorods instead of spherical nanocrystals has been shown to increase the efficiencies significantly because of the smaller number of interparticle hops necessary for the electrons to leave the device $[11,12]$. However, the nanorods have a tendency to lie in the plane of the film, which is not the optimum arrangement to extract electrons. To avoid this tendency, Baoquan Sun et al. reported the synthesis of branched CdSe nanoparticles, which led to an improvement in the efficiency by optimizing microstructure design [13].

Herein, we report the preparation of photovoltaic devices that layer $\mathrm{ZnO}$ nanowires on poly (2-methoxyl-5-(2'-ethylhexyloxy)-1,4-phenylenevinylene) (MEH-PPV). This polymer was chosen because of its formation characteristics and its stable emission properties [14]. $\mathrm{ZnO}$ nanowires were chosen as the n-type semiconductor because of their inexpensive and environmentally friendly nature. In particular, $\mathrm{ZnO}$ nanowires have shown promise for enhancing the power conversion efficiencies of conjugated polymer-based solar cells.

$\mathrm{ZnO}$ nanowires have been synthesized on $\mathrm{Cu}$ substrates through a modified vapor phase transport deposition process using a tube reactor [15-17]. The density and the reciprocal linking of the nanowires can be modified through mixing the nanowires that separated from the substrates with the 


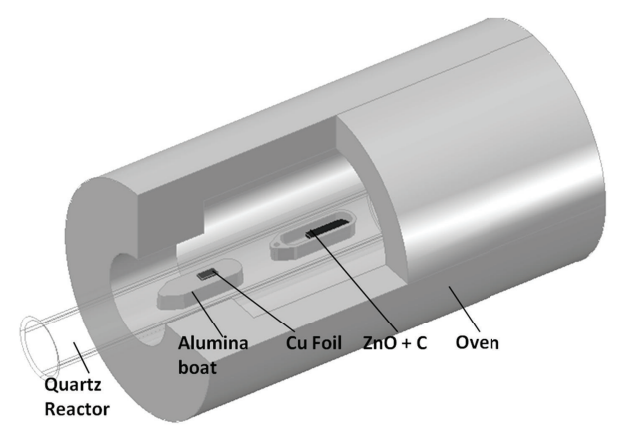

FIgURE 1: Schematic of the reactor to fabricate $\mathrm{ZnO}$ nanowires.

polymer. In this work, the $\mathrm{ZnO}$ nanowires, which formed on the $\mathrm{Cu}$ substrates, were used directly as negative electrode materials for the photovoltaic devices. To fabricate the active layer, the dissolved MEH-PPV polymer was spin-coated on the nanowires. The photovoltaic devices were made with the structure of ITO/PSS : PEDOT/MEH-PPV-ZnO/Cu, and the photovoltaic properties of the device were investigated.

\section{Experimental}

2.1. MEH-PPV Synthesis. MEH-PPV was prepared using the Gilch route [18, 19]. First, $0.05 \mathrm{~mol} \mathrm{p-hydroxyanisole}$ and $50 \mathrm{~mL}$ sodium ethoxide ethanol solution were added into a four-neck flask $(250 \mathrm{~mL})$ equipped with a condenser and stirrer and reacted at $80^{\circ} \mathrm{C}$ in $\mathrm{N}_{2}$ under reflux for $90 \mathrm{~min}$. Then, $i$-octyl bromide was added drop wise into the solution, and the reaction was refluxed at $80^{\circ} \mathrm{C}$ for $5 \mathrm{~h}$. The product [1-methoxy-4-(2-ethylhexyl)oxy]benzene (MEB) was obtained as a yellowish solid in room temperature. To as-synthesized MEB in an ice bath was added $50 \mathrm{~mL}$ 1,4-dioxane, certain amount of formaldehyde, concentrated $\mathrm{HCl}$, and paraformaldehyde (the molar ratio of double ether, formaldehyde and concentrated $\mathrm{HCl}$ was $\sim 1: 10: 10)$. The mixture was transferred to a four-neck flask, refluxed at $90^{\circ} \mathrm{C}$ in the presence of absolute $\mathrm{AlCl}_{3}$ for $5 \mathrm{~h}$, and then cooled to room temperature. A rotatory evaporation process was used for the removal of 1,4-dioxane. The remnant was treated by crystallization and was followed by recrystallization in a mixture of n-heptane and ice methanol with a volume ration of $1: 1$ (by volume). [1,4-Dichloromethyl-2-methoxy-5-(2ethylhexyl)oxy]benzene (DMEB) were obtained through filtration, and the solid was washed by ethanol and dried under vacuum. To a solution of $0.0025 \mathrm{~mol} \mathrm{DMEB}$ in $10 \mathrm{~mL}$ tetrahydrofuran (THF) was added dropwise a fresh potassium t-butoxide THF solution $\left[\left(\mathrm{CH}_{3}\right)_{3} \mathrm{COK}\right.$ : THF = $1: 1.6$ (mole ratio)] in a three-neck flask $(25 \mathrm{~mL})$. The mixture was refluxed with $\mathrm{N}_{2}$ protection at $66^{\circ} \mathrm{C}$ for $2 \mathrm{~h}$. The color of solution changed gradually from colorless to yellow and to dark orange. Then $10 \mathrm{~mL}$ methanol was added to the mixture and reacted for $10 \mathrm{~min}$. THF was removed by rotary evaporation, and the MEH-PPV powder was washed successively with absolute ethanol and distilled water and separated by vacuum filtrations.

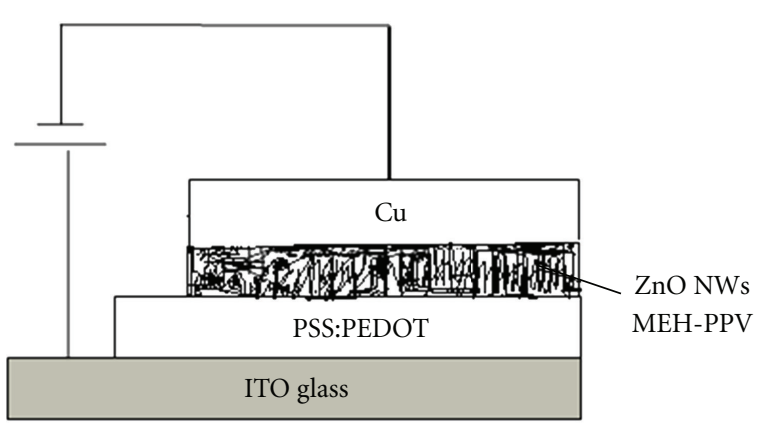

FIgure 2: Photovoltaic device structure.

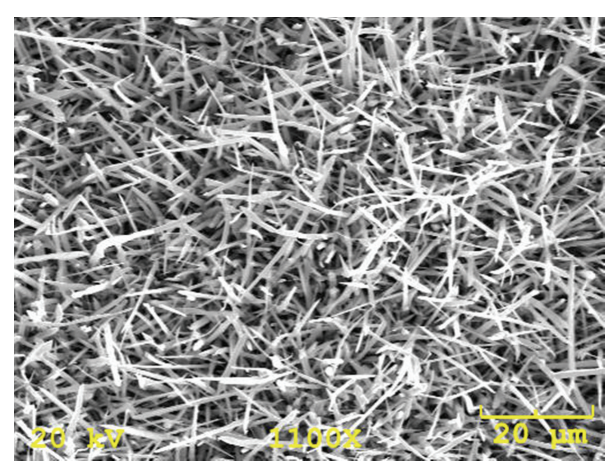

FIgURe 3: SEM image of $\mathrm{ZnO}$ nanowires.

The $M_{w}$ of MEH-PPV was $5.73 \times 10^{4}$, and it has a polydispersity of 1.04 as measured by a Waters 1515 GPC instrument using styragel-1000 columns and THF as the mobile phase. MEH-PPV: ${ }^{1} \mathrm{HNMR}, \delta 1.18 \sim 1.80(9 \mathrm{H}$, methene, $\delta 0.82$ (6H, methyl), $\delta 4.66(2 \mathrm{H}$, ethylene), $\delta 6.83(2 \mathrm{H}$, aromatic protons), $\delta 7.14\left(3 \mathrm{H},-\mathrm{OCH}_{3}\right)$, and $\delta 3.69\left(4 \mathrm{H},-\mathrm{OCH}_{2}\right)$. The ${ }^{1} \mathrm{HNMR}$ spectra were collected on a Bruker Avance 400 spectrometer using chloroform- $d$ as the solvent and tetramethylsilane as the internal standard.

2.2. $\mathrm{ZnO}$ Nanowire Synthesis. quartz reactor with a sealed end was used to grow $\mathrm{ZnO}$ nanowires with no gas flow. The construction of the reactor is shown in Figure 1.

2.3. Preparation of Photovoltaic Devices. A 4-mL solution of MEH-PPV (0.5 mg/mL in chloroform) was spin-coated onto the $\mathrm{ZnO}$ nanowires on the $\mathrm{Cu}$ substrate by dropwise. Then, $1.5 \%$ of PSS : PEDOT (Aldrich) was spin-coated onto the ITO glass substrates. These samples were dried at $100^{\circ} \mathrm{C}$ in $\mathrm{He}$ for $10 \mathrm{~min}$ as the counter electrode. The thickness of PSS : PEDOT was approximately $50 \mathrm{~nm}$. The photovoltaic device was fabricated in sandwich structures as shown in Figure 2.

\section{Results and Discussion}

The surface topography of the $\mathrm{ZnO}$ nanowires was studied using atomic force microscopy (JEOL-6100) as shown in Figure 3. A large fraction of the $\mathrm{ZnO}$ nanowires was obtained 


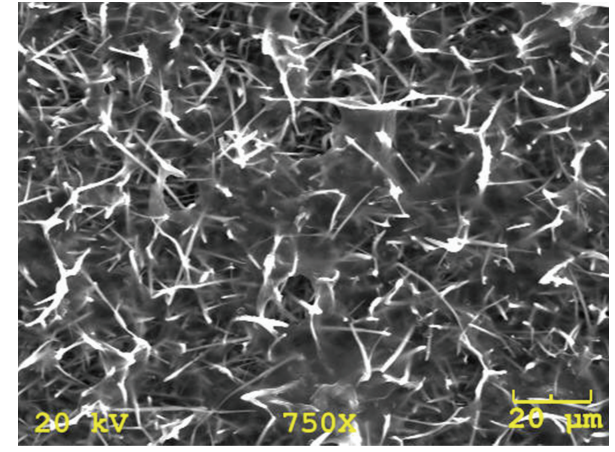

FIGURE 4: SEM image of $\mathrm{ZnO}$ nanowires overlaid on MEH-PPV.

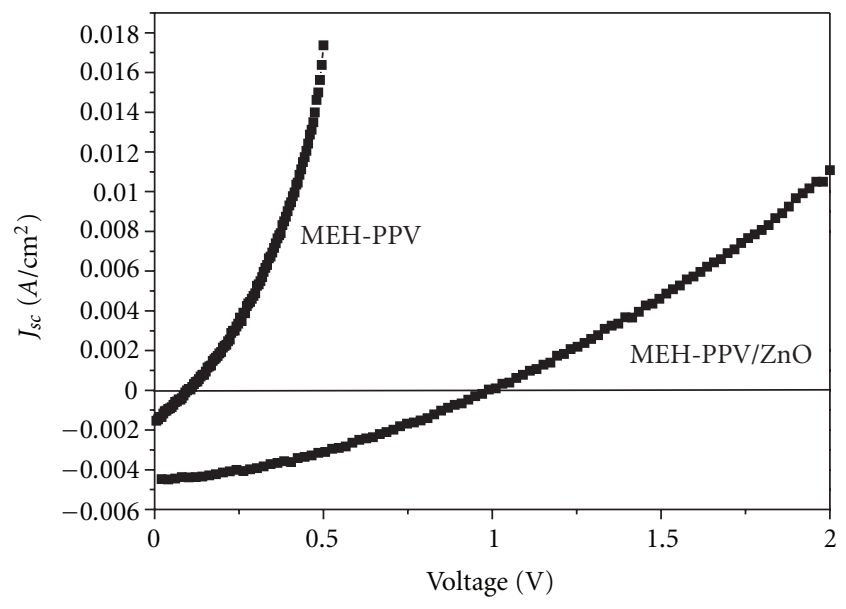

FIgURE 5: Current density versus voltage for the MEH-PPV and $\mathrm{MEH}-\mathrm{PPV} / \mathrm{ZnO}$ device under illumination at AM 1.5 $\left(100 \mathrm{~mW} / \mathrm{cm}^{2}\right)$.

without selective precipitation. These nanowires have an average diameter of $0.8-1 \mu \mathrm{m}$ and a length of approximately $20 \mu \mathrm{m}$. The nanowires did not agglomerate during the growth process; however, they were interlaced and scattered randomly throughout the substrate. Figure 4 showed that the polymer films were soaked into the $\mathrm{ZnO}$ nanowires, and this observation confirmed that the polymer and the inorganic nanowires combined at a micrometer scale.

Figure 5 shows the current density as a function of the voltage for the photovoltaic device. The devices were illuminated at the transparent ITO electrode. The $J-V$ characteristics were measured with a computer-controlled Keithley 2420 source meter under illumination at AM 1.5 $\left(100 \mathrm{~mW} / \mathrm{cm}^{2}\right)$. The short-circuit current density $\left(J_{\mathrm{sc}}\right)$, opencircuit voltage $\left(V_{\mathrm{oc}}\right)$, fill factor $(\mathrm{FF})$, and power conversion efficiency $(\eta)$ of the two photovoltaic devices are shown in Table 1.

Under illumination at AM $1.5\left(100 \mathrm{~mW} / \mathrm{cm}^{2}\right)$, the solar power conversion efficiency of the $\mathrm{MEH}-\mathrm{PPV} / \mathrm{ZnO}$ nanowire device is $1.37 \%$, and the short-circuit current density $\left(J_{\text {sc }}\right)$ and the open-circuit voltage $\left(V_{\mathrm{oc}}\right)$ are $0.0045 \mathrm{~A} / \mathrm{cm}^{2}$ and $1.01 \mathrm{~V}$, respectively. These values were slightly higher than those of the MEH-PPV devices. This result proves that the
TABLE 1: Characteristics of the device made with MEH-PPV and $\mathrm{MEH}-\mathrm{PPV} / \mathrm{ZnO}$.

\begin{tabular}{lllll}
\hline Active layer & $J_{\mathrm{sc}}\left(\mathrm{A} / \mathrm{cm}^{2}\right)$ & $V_{\mathrm{oc}}(\mathrm{V})$ & $\mathrm{FF}$ & $\eta(\%)$ \\
\hline MEH-PPV & 0.00196 & 0.095 & 0.25 & 0.047 \\
MEH-PPV/ZnO & 0.0045 & 1.01 & 0.26 & 1.37 \\
\hline
\end{tabular}

function of the nanowires is to increase the electron mobility and reduce the electron recombination rate within the conjugated polymer. Specifically, the nanowires provide a heterojunction interface that dissociates the photogenerated excitons into electrons and holes. Due to their high-energy electronic band structure, the nanowires provide a direct conduit for electrons to be transported to the device electrode, where they can contribute to current conduction [20].

We found that the polymer was evenly covered with the nanowires; however, some holes were observed on the surface of the sample. These residual air holes greatly impacted the device performance and reduced FF. The device resistance would increase and its FF decrease with increasing polymer film thickness. Therefore, the FF of the MEH-PPV/ZnO nanowire device did not increase significantly.

Our results indicate that the use of nanowires is an attractive route to obtain highly efficient photovoltaic devices by improving electron transport perpendicular to the plane of the film. Future improvements in efficiency are likely to involve the optimization of electron extraction through the nanowire network and the improvement of hole transport in the polymer.

\section{Conclusions}

$\mathrm{ZnO}$ nanowires have been synthesized by a vapor transport deposition process. SEM data indicated that the $\mathrm{ZnO}$ nanowires were coated by polymer and a micrometerscale combination was achieved. Bulk-heterojunction photovoltaic devices based on MEH-PPV combined with inorganic semiconductor $\mathrm{ZnO}$ nanowires were made. The short-circuit current density $\left(J_{\mathrm{sc}}\right)$, open-circuit voltage $\left(V_{\mathrm{oc}}\right)$, fill factor $(\mathrm{FF})$, and power conversion efficiency $(\eta)$ of the optimum device are $0.0045 \mathrm{~A} / \mathrm{cm}^{2}, 1.01 \mathrm{~V}$, and $1.37 \%$, respectively. The power conversion efficiency was slightly higher than that of MEH-PPV devices, illustrating the effectiveness of the combination of conjugated polymers and inorganic semiconductor nanowire materials for photovoltaic applications.

\section{Acknowledgments}

The authors thank Professors Liu Xijun and Lu Xinkun for helpful discussions and assistance. This work is supported by the project of Qiqihar University young teacher's scientific research.

\section{References}

[1] S. C. Veenstra, W. J. H. Verhees, J. M. Kroon et al., "Photovoltaic properties of a conjugated polymer blend of MDMO-PPV 
and PCNEPV," Chemistry of Materials, vol. 16, no. 12, pp. 2503-2508, 2004.

[2] P. Schilinsky, C. Waldauf, and C. J. Brabec, "Recombination and loss analysis in polythiophene based bulk heterojunction photodetectors," Applied Physics Letters, vol. 81, no. 20, pp. 3885-3887, 2002.

[3] M. M. Wienk, J. M. Kroon, W. J. H. Verhees et al., "Efficient methano[70]fullerene/MDMO-PPV bulk heterojunction photovoltaic cells," Angewandte Chemie. International Edition, vol. 42, no. 29, pp. 3371-3375, 2003.

[4] Y. Cao, I. D. Parker, G. Yu, C. Zhang, and A. J. Heeger, "Improved quantum efficiency for electroluminescence in semiconducting polymers," Nature, vol. 397, no. 6718, pp. 414-415, 1999.

[5] H. Becker, H. Spreitzer, W. Kreuder et al., "Soluble PPVs with enhanced performance-a mechanistic approach," Advanced Materials, vol. 12, no. 1, pp. 42-48, 2000.

[6] W. J. E. Beek, M. M. Wienk, and R. A. J. Janssen, "Efficient hybrid solar cells from zinc oxide nanoparticles and a conjugated polymer," Advanced Materials, vol. 16, no. 12, pp. 1009-1013, 2004.

[7] W. J. E. Beek, M. M. Wienk, M. Kemerink, X. Yang, and R. A. J. Janssen, "Hybrid zinc oxide conjugated polymer bulk heterojunction solar cells," Journal of Physical Chemistry B, vol. 109, no. 19, pp. 9505-9516, 2005.

[8] W. U. Huynh, J. J. Dittmer, and A. P. Alivisatos, "Hybrid nanorod-polymer solar cells," Science, vol. 295, no. 5564, pp. 2425-2427, 2002.

[9] S. A. McDonald, G. Konstantatos, S. Zhang et al., "Solutionprocessed $\mathrm{PbS}$ quantum dot infrared photodetectors and photovoltaics," Nature Materials, vol. 4, no. 2, pp. 138-142, 2005.

[10] A. A. R. Watt, D. Blake, J. H. Warner et al., "Lead sulfide nanocrystal: conducting polymer solar cells," Journal of Physics D, vol. 38, no. 12, pp. 2006-2012, 2005.

[11] B. Sun, E. Marx, and N. C. Greenham, "Photovoltaic devices using blends of branched CdSe nanoparticles and conjugated polymers," Nano Letters, vol. 3, no. 7, pp. 961-963, 2003.

[12] D. Braun and A. J. Heeger, "Visible light emission from semiconducting polymer diodes," Applied Physics Letters, vol. 58, no. 18, pp. 1982-1985, 1991.

[13] S. H. Jung, H. K. Kim, S. H. Kim, Y. H. Kim, S. C. Jeoung, and D. Kim, "Palladium-catalyzed direct synthesis, photophysical properties, and tunable electroluminescence of novel siliconbased alternating copolymers," Macromolecules, vol. 33, no. 25, pp. 9277-9288, 2000.

[14] X. Wu, G. Shi, F. Chen, S. Han, and J. Peng, "High-quality poly[2-methoxy-5-(2'-ethylhexyloxy)-p-phenylenevinylene] synthesized by a solid-liquid two-phase reaction: characterizations and electroluminescence properties," Journal of Polymer Science A, vol. 42, no. 12, pp. 3049-3054, 2004.

[15] Z. R. Dai, Z. W. Pan, and Z. L. Wang, "Novel nanostructures of functional oxides synthesized by thermal evaporation," Advanced Functional Materials, vol. 13, no. 1, pp. 9-24, 2003.

[16] H. Ham, G. Shen, J. H. Cho, T. J. Lee, S. H. Seo, and C. J. Lee, "Vertically aligned $\mathrm{ZnO}$ nanowires produced by a catalystfree thermal evaporation method and their field emission properties," Chemical Physics Letters, vol. 404, no. 1-3, pp. 6973, 2005.

[17] D. Yu, T. Trad, J. T. McLeskey, V. Craciun, and C. R. Taylor, "ZnO nanowires synthesized by vapor phase transport deposition on transparent oxide substrates," Nanoscale Research Letters, vol. 5, no. 8, pp. 1333-1339, 2010.
[18] Y. Suzuki, K. Hashimoto, and K. Tajima, "Synthesis of regioregular poly(p-phenylenevinylene)s by horner reaction and their regioregularity characterization," Macromolecules, vol. 40, no. 18, pp. 6521-6528, 2007.

[19] C. J. Neef and J. P. Ferraris, "MEH-PPV: improved synthetic procedure and molecular weight control," Macromolecules, vol. 33, no. 7, pp. 2311-2314, 2000.

[20] H. E. Unalan, P. Hiralal, D. Kuo, B. Parekh, G. Amaratunga, and M. Chhowalla, "Flexible organic photovoltaics from zinc oxide nanowires grown on transparent and conducting single walled carbon nanotube thin films," Journal of Materials Chemistry, vol. 18, no. 48, pp. 5909-5912, 2008. 

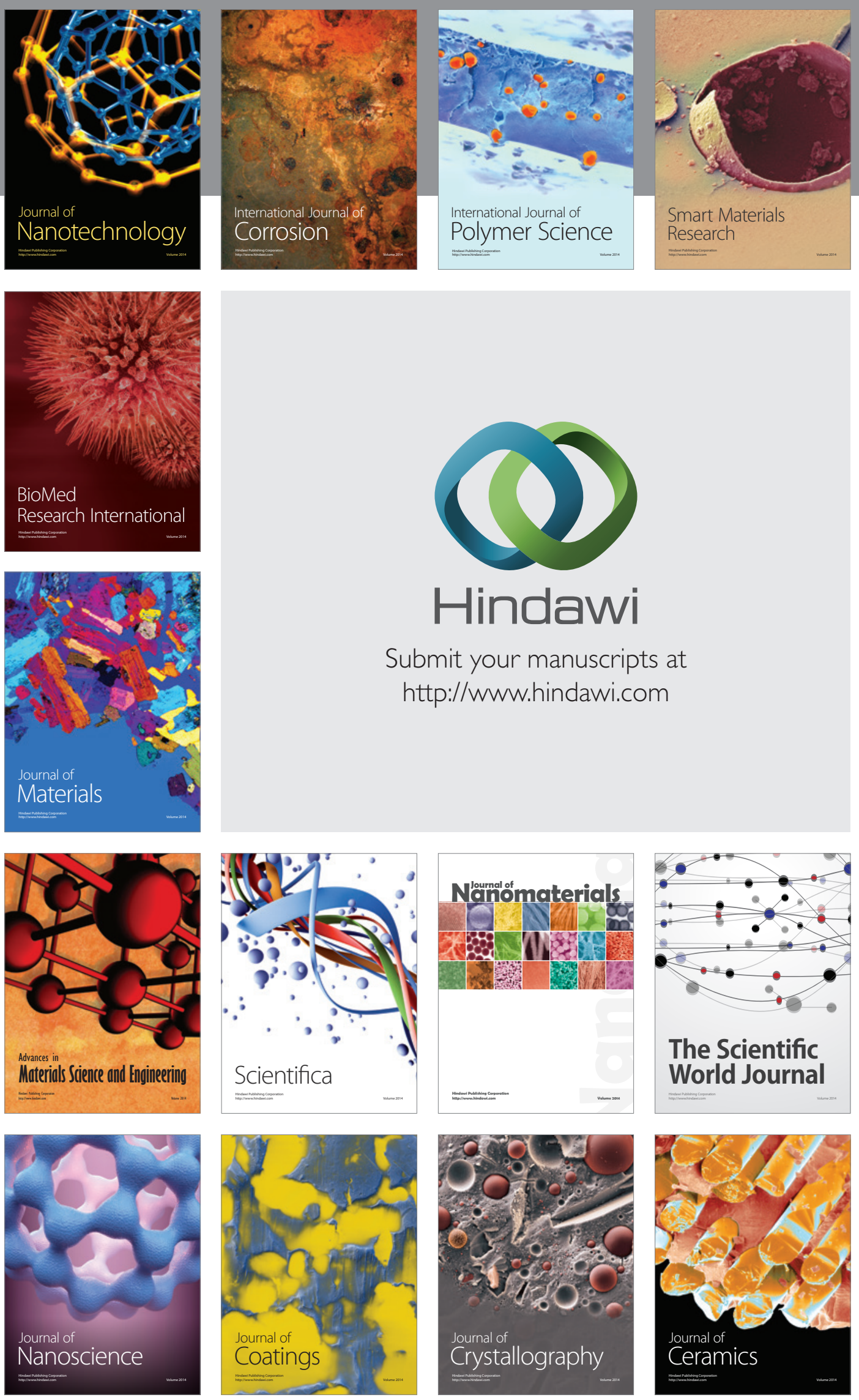

The Scientific World Journal

Submit your manuscripts at

http://www.hindawi.com

\section{World Journal}

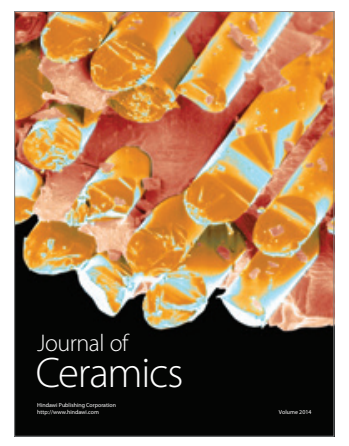

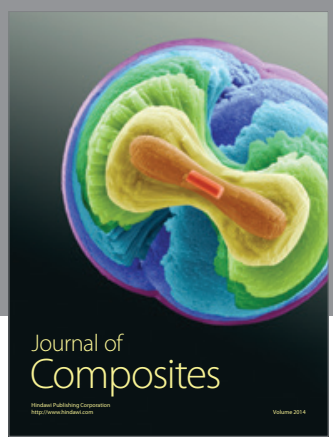
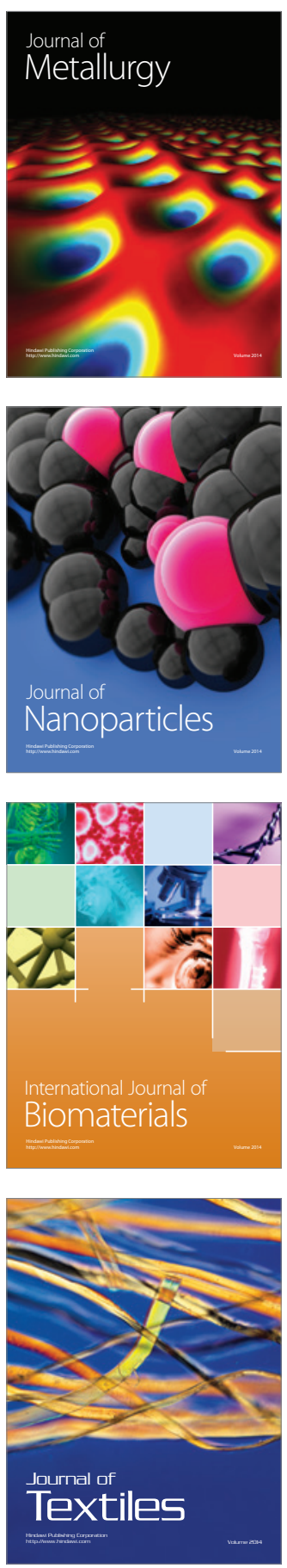